\section{Gategory}

Metal-Catalyzed Asymmetric

Synthesis and

Stereoselective

Reactions

\section{Key words}

rhodium

vinylogous addition

silyl enol ethers

siloxyvinyldiazoacetate

\section{chiral}

tetracarboxylate

ligands

A. G. SMITH, H. M. L. DAVIES* (EMORY UNIVERSity, ATLANTA, USA)

Rhodium-Catalyzed Enantioselective Vinylogous Addition of Enol Ethers to Vinyldiazoacetates

J. Am. Chem. Soc. 2012, 134, 18241-18244.

\title{
Rhodium-Catalyzed Asymmetric Vinylogous Addition to Vinyldiazoacetates
}

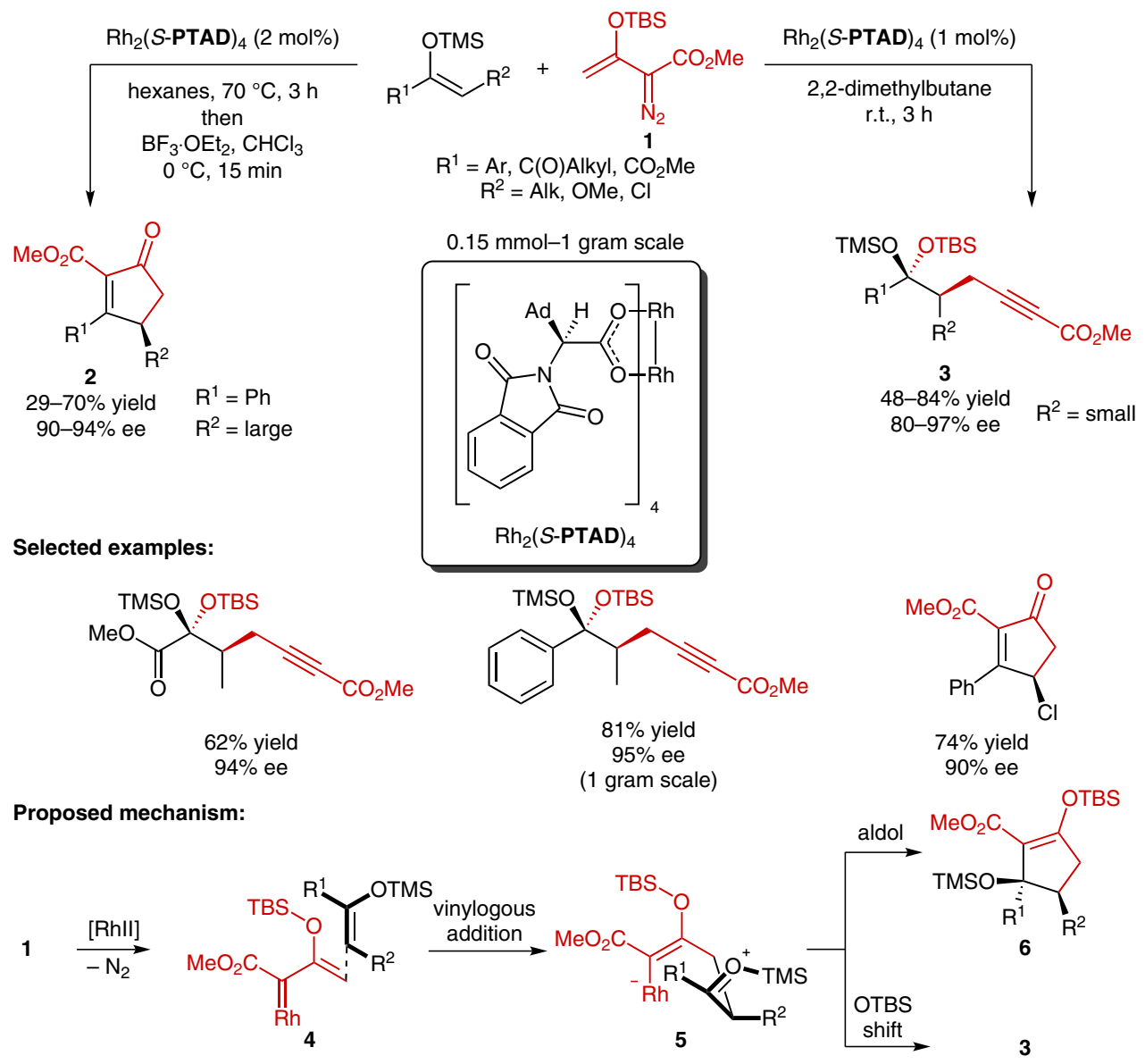

Significance: A rhodium-catalyzed asymmetric vinylogous addition of silyl enol ethers to siloxyvinyldiazoacetates is reported. Depending on the sterics of the substituents on the substrate, this method can access cyclopentenones 2 or alkynoates $\mathbf{3}$ with high yield and excellent enantioselectivity.
Comment: The use of (Z)-silyl enol ethers is critical in achieving the observed enantioselectivity. In the proposed mechanism, vinylogous adduct $\mathbf{5}$ can undergo a stereoselective 1,4-silyoxy shift to form 3. Bulkier $R^{1}$ groups favor the aldol reaction to form formal [3+2] adduct $\mathbf{6}$, which in one pot, in acid, can afford 2. 